\title{
Burnout and Resilience in Community Pharmacists in Qatar during the COVID-19 Pandemic: a Cross Sectional Study
}

\author{
Zeana Alkudsi ${ }^{1}$, Nadin Kamel ${ }^{1}$, Alla El-Awaisi ${ }^{1}$, Mujahed M A Shraim², Maguy Elhajj ${ }^{1^{*}}$ \\ ${ }^{1}$ College of Pharmacy, QU Health, Qatar University, Doha, Qatar, *Principle Investigator \\ ${ }^{2}$ College of Health Sciences, QU Health, Qatar University, Doha, Qatar
}

\section{Background}

Community pharmacists are the most accessible healthcare providers during the pandemic which puts them at risk for experiencing mental health issues.

- Burnout is an occupational phenomenon that is defined by the World Health Organization (WHO) as chronic workplace stress (1).

- Resilience is the process of adapting and the ability of bouncing back when facing adversity, tragedy, trauma, or stress (2).

- Many studies have identified moderate to high levels of burnout among HCP; however, little is known about this syndrome in Qatar.

\section{Study Objectives}

- Characterize the level of burnout and resilience among community pharmacists during the COVID-19 outbreak in Qatar.

- Assess the symptoms of stress, anxiety, depression and fear in community pharmacists in Qatar.

\section{Methods}

\section{Study Design}

- A cross-sectional survey of community pharmacists was conducted in Qatar. Pharmacists who were licensed and practicing in community pharmacies in Qatar were eligible to participate in the study.

\section{Survey implementation}

- Qatar Ministry of Public Health (MoPH) database was used to randomly select a sample of community pharmacists in Qatar using Statistical Package for Social Sciences (SPSS $®$ ) version 27

\section{Survey Measures}

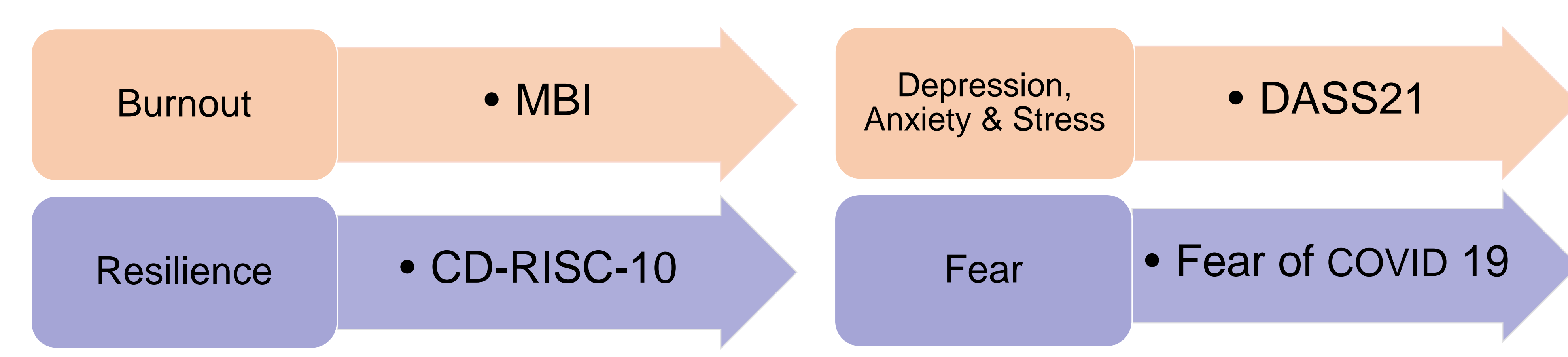

\section{Data Analysis}

- Data were analyzed using SPSS ${ }^{\circledR}$ version 27

- Descriptive statistics were used to report frequencies and percentages for categorical variables and mean \pm standard deviation for continuous variables.

- Chi-square test, Independent two-sample t-test and Pearson correlation coefficient were used to examine any differences in the study outcomes between multiple pharmacists' characteristics.

\section{Resultis}

- 103 community pharmacists out of 330 (31.2\%).

Table 1. Pharmacists' Sociodemographic

\begin{tabular}{|c|c|c|}
\hline Characteristic & $\begin{array}{c}\text { Mean (SD) } \\
36.85(8.238)\end{array}$ & Frequency (Percent) \\
\hline $\begin{array}{l}\text { Gender (N=102) } \\
\text { Male } \\
\text { Female }\end{array}$ & & $\begin{array}{l}61(59.8 \%) \\
41(40.2 \%)\end{array}$ \\
\hline $\begin{array}{l}\text { Country of origin (N=102) } \\
\text { Arabs } \\
\text { Non-Arabs }\end{array}$ & & $\begin{array}{l}46(45.3 \%) \\
56(54.7 \%)\end{array}$ \\
\hline 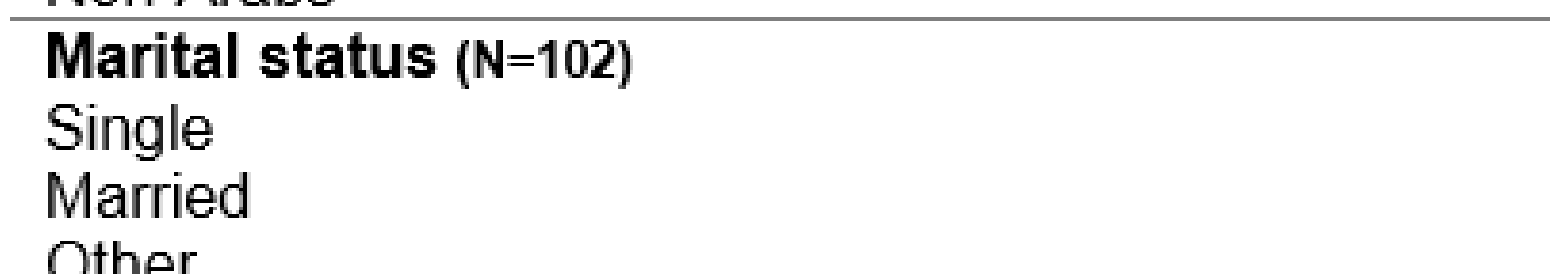 & & $\begin{array}{l}19(18.6 \%) \\
76(7.5 \%) \\
770 \%)\end{array}$ \\
\hline Number of children $(\mathrm{N}=78)$ & $1.68(1.157)$ & \\
\hline $\begin{array}{l}\text { Current living arrangement (N=102) } \\
\text { Alone } \\
\text { With family } \\
\text { With coworkers }\end{array}$ & & $\begin{array}{l}33(32.4 \%) \\
55(55.9 \%) \\
13(12.7 \%)\end{array}$ \\
\hline $\begin{array}{l}\text { Highest pharmacy degree (N=101) } \\
\text { PBharm/BSc Pharm } \\
\text { PharmD } \\
\text { MPharm } \\
\text { MSc }\end{array}$ & & $\begin{array}{l}71(70.3 \%) \\
8(7.9 \%) \\
18(11.8 \%) \\
4(4.0 \%)\end{array}$ \\
\hline $\begin{array}{l}\text { Community pharmacy type (N=101) } \\
\text { IIndependent single pharmacy } \\
\text { Chain pharmacy } \\
\text { Other }\end{array}$ & & $\begin{array}{l}16(15.8 \%) \\
7977.2 \%)\end{array}$ \\
\hline $\begin{array}{l}\text { Tyer of employment (N=102) } \\
\text { Part time } \\
\text { Full time }\end{array}$ & & $\begin{array}{l}5(5.9 .9) \\
57(4.9 \%) \\
9(95.1 \%)\end{array}$ \\
\hline Average hours of work per week in pharmacy $(\mathrm{N}=98)$ & $45.58(13.603)$ & \\
\hline Approximate patients per day $(\mathrm{N}=100)$ & $76.28(72.292)$ & \\
\hline 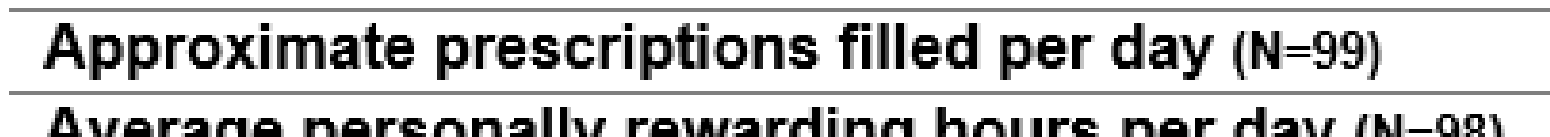 & $22.98(40.921)$ & \\
\hline $\begin{array}{l}\text { Average personally rewarding hours per day }(\mathbb{N}=98) \\
\text { Tlinic pharmacy, warenouse }\end{array}$ & & \\
\hline
\end{tabular}

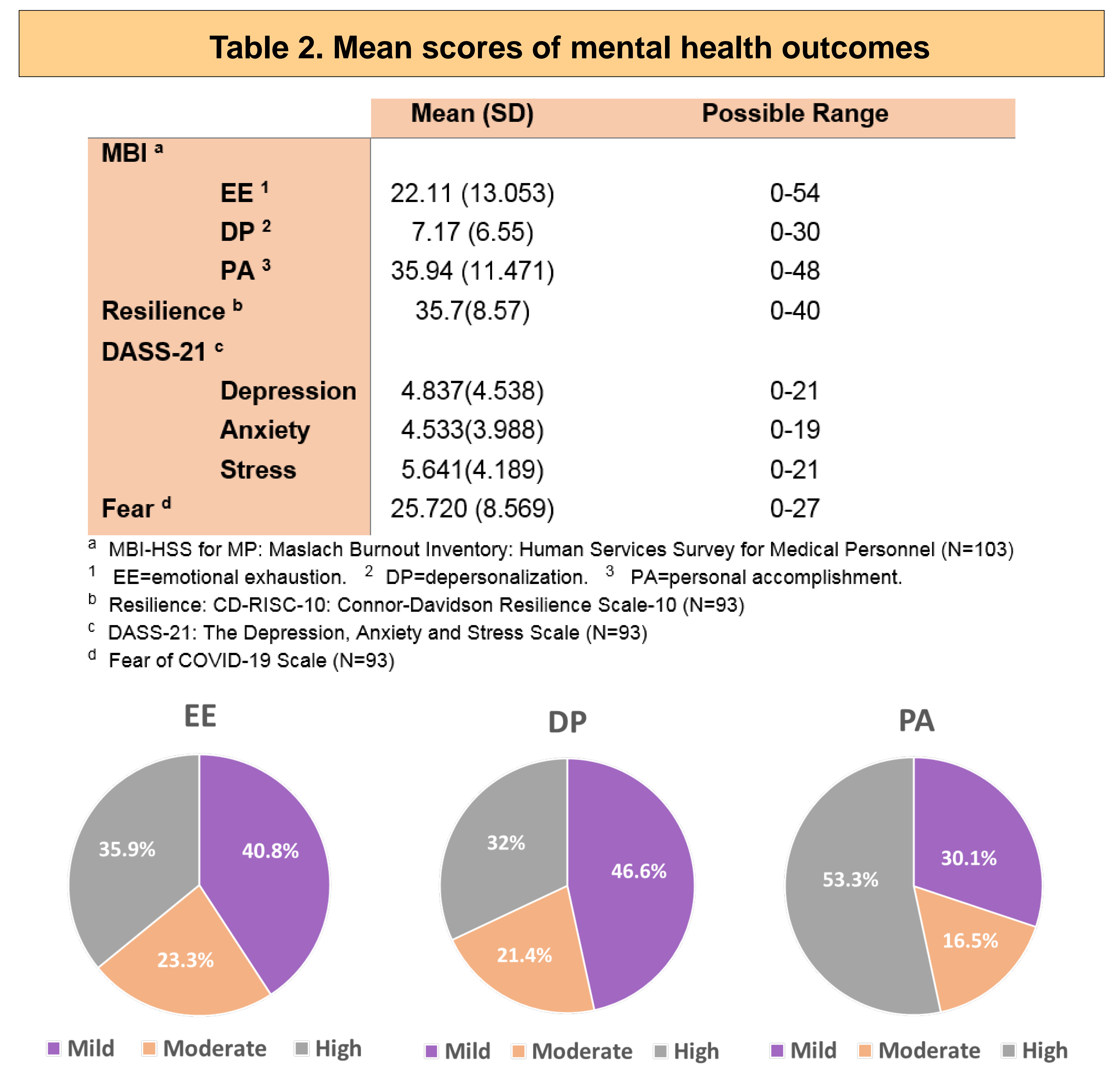

Figure 1. Percentage of severity categories for MBI

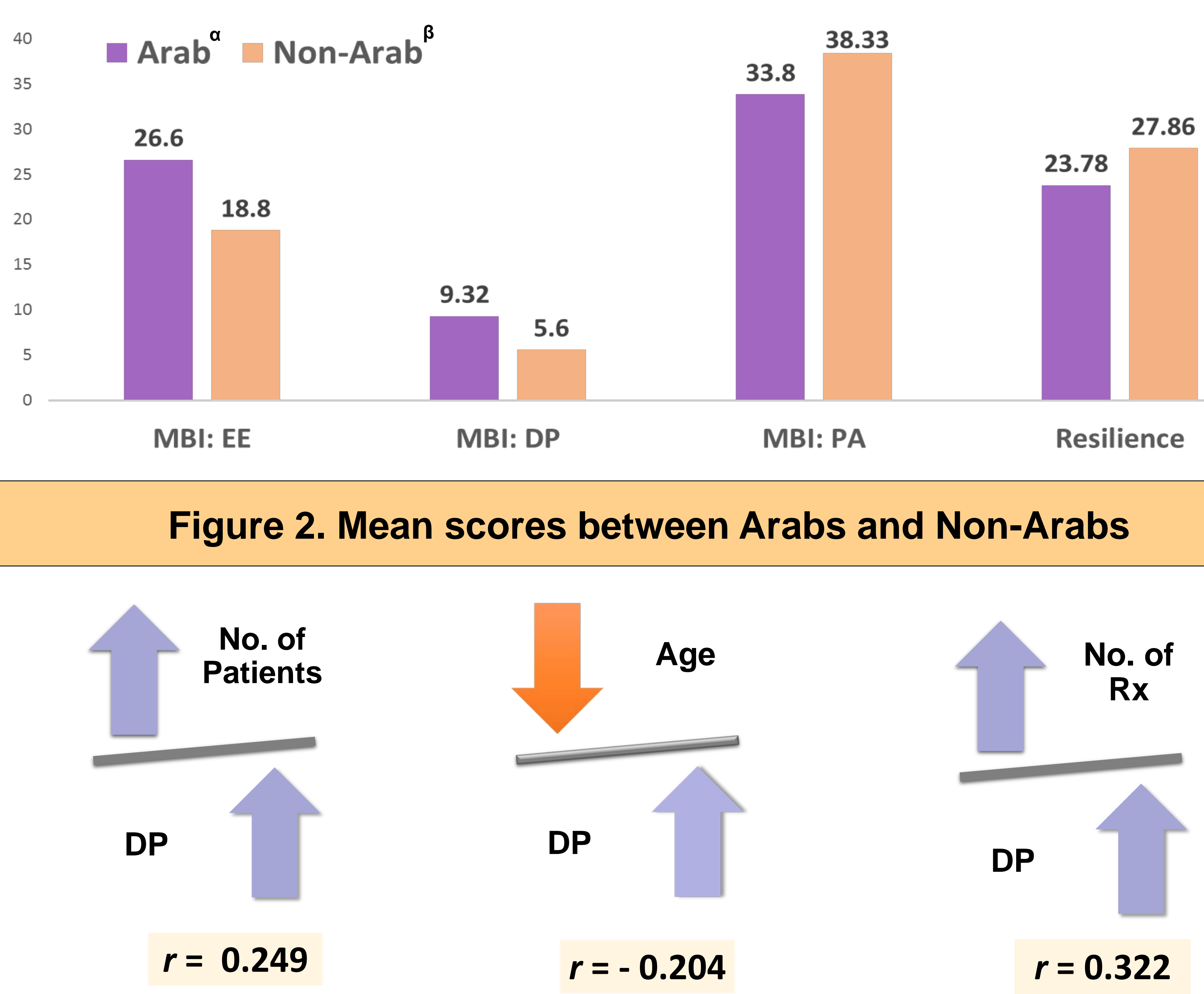

Figure 3. Correlation between MBI:DP and characteristics

Linsitalions

- Small sample size (low response rate).

- Social desirability bias might have affected the results.

Conctusions

- The pharmacists experienced moderate burnout but high resilience, which indicates their high potential to overcome difficulties.

- The levels of fear were high, however there were low levels of depression, stress, and anxiety.

- For future research, longitudinal and qualitative studies are recommended, to develop and implement psychological interventions to improve burnout. 